\title{
Cognitive consequences of bilingualism: where to go from here?
}

\author{
Matti Laine \& Minna Lehtonen
}

Department of Psychology, Åbo Akademi University, Turku, Finland

Running head: Cognitive consequences of bilingualism

Address for correspondence: Matti Laine, Department of Psychology, Åbo Akademi University, Fabriksgatan 2, 20500 Turku, Finland. Email matti.laine@abo.fi 


\begin{abstract}
The present short review discusses reasons for the mixed results on the possible enhancement of cognition, especially executive function, in bilingualism. We define three major problem areas that hamper many studies in this field: the use of research designs that are weak for the task at hand, the lack of a detailed theory on how bilingual experience would modify cognition, and the employment of measures of bilingual behaviour and executive function that are troublesome. Potential remedies for these problem areas are discussed, and the emerging research approach where specific aspects of individual bilingual experience are examined and related to specific aspects of executive performance is highlighted.
\end{abstract}

Keywords: bilingualism, executive functions, cognition, bilingual advantage 


\section{Introduction}

Research on the relationships between bilingualism and cognition dates back almost a century, with a dramatic shift from very negative early views (e.g., Saer, 1923) to more recent proposals on bilingual enhancements especially concerning executive functions (e.g., Bialystok, Craik \& Luk, 2012), thought to result from long-term practice in managing two or more languages that trains executive skills. The widespread interest in this research topic is due to several factors. At the theoretical level, bilingualism provides an avenue for research on language learning mechanisms, language-cognition interfaces, and brain plasticity in general. At the practical level, bilingualism is related to important societal, cultural and educational issues. Thus, it is not surprising that the putative bilingual executive advantage (BEA) has attracted considerable research interest that has lately turned into a controversy on the existence of BEA (see e.g. the keynote papers by Baum \& Titone, 2014, and Paap, Johnson \& Sawi, 2015, and the ensuing commentaries). The aim of this selective review is to provide a short summary on what we consider to be the main problems in BEA research that have led to this controversy, and to highlight recent approaches to tackle these problems. In this way, we hope to provide the interested reader with an easily digestible overview on crucial issues that currently lie somewhat scattered in the literature. Rather than trying to cover the whole field, or taking a stance for or against the BEA hypothesis, we highlight the key methodological and theoretical challenges that need to be solved until valid conclusions can be made.

Since its start in the 1960s, modern research on the cognitive consequences of bilingualism has provided a number of studies indicating better performance in bilinguals than in monolinguals on a wide range of tasks tapping attention, inhibitory skills, task switching, metacognition, divergent thinking, and problem solving (see, e.g., Adesope, Lavin, Thompson \& Ungerleider, 2010, and Bialystok et al., 2012, for reviews). A more recent, intriguing finding from retrospective studies has been the possible delay in the onset of dementia symptoms in bilinguals 
that could hint for additional cognitive reserve for bilinguals compared to monolinguals (e.g., Alladi et al., 2013; Bialystok, Abutalebi, Bak, Burke \& Kroll, 2016; Bialystok, Craik \& Freedman, 2007). Nevertheless, the few prospective studies on this topic have failed to confirm this finding (for a meta-analysis, see Mukadam, Sommerlad, \& Livingston, 2017; see also Ljungberg, Hansson, Adolfsson, \& Nilsson, 2016). Moreover, several neuroimaging studies have reported both structural and functional differences between bilingual and monolingual participants (e.g., Abutalebi, Canini, Della Rosa, Green, \& Weekes, 2015; Costa \& Sebastián-Gallés, 2014; Garbin et al., 2010; Hämäläinen, Sairanen, Leminen \& Lehtonen, 2017; Mechelli et al., 2004; Perani \& Abutalebi, 2005), and longitudinal imaging studies on foreign language learning have revealed brain changes over time (e.g,, Mårtensson et al., 2012). However, the pattern and significance of the bilingualismrelated neuroimaging findings is not quite clear (for a recent review, see Garcia-Penton, Fernández García, Costello, Duñabeitia \& Carreiras, 2016). In addition, negative or null findings on bilingualmonolingual cognitive differences have also been reported (e.g., Antón et al., 2014; Duñabeitia et al., 2014; Morton \& Harper, 2007; Hilchey \& Klein, 2011; Paap \& Greenberg, 2013; Paap, Johnson $\&$ Sawi, 2014), prompting recent reviews and meta-analyses on the literature.

To briefly highlight some of these overviews, the meta-analysis by Adesope et al. (2010) on the cognitive correlates of bilingualism analyzed 63 studies that contrasted proficient bilinguals with monolinguals on cognitive measures including attentional control, problem-solving skills, creative and divergent thinking, cognitive flexibility, learning strategies, symbolic representation and abstract reasoning skills, metalinguistic awareness, metacognitive skills, and working memory. They reported moderate overall positive effects of bilingualism and no signs of publication bias, but there was large variation in the effect sizes between the cognitive domains, with the highest effect size for attentional control. As the executive skill of ignoring irrelevant information has been a prominent topic in BEA research, a review by Hilchey \& Klein (2011) focused on inhibitory measures. They observed a global bilingual performance advantage 
irrespective of inhibitory demands but evidence for a BEA in inhibitory skills was scant. In a reanalysis by Hilchey, Saint-Aubin and Klein (2016) that included more recent studies, also the global performance advantage failed to appear. More recent narrative reviews by Bialystok and colleagues concluded that BEA is more readily observable in children and elderly (possibly because they are not at the peak of their executive skills as young adults are), and that the underlying cognitive advantage could be related to more general attentional control rather than a specific executive component such as improved inhibition of irrelevant stimuli (Bialystok et al., 2012; Bialystok, 2015). Also these conclusions have been countered by large-scale studies in children that do not show BEA (Antón,et al., 2014; Duñabeitia et al., 2014; Gathercole et al., 2014). A very recent extensive meta-analysis of 152 BEA studies on adults did not find any evidence for larger bilingualmonolingual differences in older adults either (Lehtonen, Soveri, Laine, Järvenpää \& de Bruin, in press). Moreover, young adults are not necessarily performing even simpler executive tasks at ceiling levels that could mitigate possible BEA (Paap, Wagner, Johnson, Bockelman, Cushing, \& Sawi, 2014). Finally, a recent fine-grained eye-tracking analysis failed to find bilingual advantages in attentional guidance of demanding visual search tasks (Ratiu. Hout, Walenchok, Azuma, \& Goldinger, 2017).

There are also other recent critical reviews that have challenged the existence of BEA. De Bruin, Treccani and Della Sala (2014) analyzed 104 congress abstracts on the topic, and found that those reporting BEA were most likely to get published, thus suggesting a publication bias. Publication bias is by no means specific to BEA research, and having such a bias does not as such refute the existence of an effect. In their meta-analysis of 68 experiments, Zhou and Krott (2016) noted that a seemingly minor methodological detail, trimming of RT data, has an impact on the presence or absence of BEA on interference control tasks: studies that included longer RTs in their analysis were found to be more likely to report BEA. As a part of a larger critical review, Paap, Johnson and Sawi (2015) examined the results on interference and task switching measures in 
bilinguals vs monolinguals, finding that the studies reporting BEA on these measures clustered on the lower end of $n$ (<30 participants per group) while large- $n$ studies reported null effects. In a their critical review that was accompanied by numerous commentaries, Paap et al. (op.cit.) put forth their conclusion already in the title of their paper: "Bilingual advantages in executive functioning either do not exist or are restricted to very specific and undetermined circumstances". This conclusion found support in the most recent, large-scale meta-analysis of BEA studies in adults by Lehtonen et al. (in press): after correcting for publication bias, they found no reliable evidence for BEA in the six executive domains studied (inhibition, monitoring, shifting, attention, verbal fluency, working memory).

All in all, a seemingly rather widespread earlier consensus on the existence of BEA, with its nature somewhat undefined, has turned into a strong controversy. Why have we ended up in this situation and how can we move forward?

\section{Three major problem areas in BEA research}

There can be many reasons for the mixed results concerning the existence of BEA, but here we focus on three major interrelated problem areas. Two of these are methodological and one is theoretical.

1. Research design. Typical studies on BEA select groups of bilingual and monolingual participants, try to match them on background factors such as age, gender, and education, and then run executive tests to compare the group performances. This represents a natural groups design, and it is well known that this design can provide only correlative evidence on the relationship between the independent variable (bilingualism) and the dependent variables (executive measures). In a natural groups design, causality could in principle go both ways: bilinguals become better in executive skills because of their regular long-term practice in managing 
two or more languages, or people who have better executive skills to start with might be more prone to pick up several languages. Moreover, despite matching of some demographic factors, there can always be any number of other, unknown background variables that influence the findings concerning executive skills in monolinguals vs. bilinguals.

To take the research design issue further, we think that it is instructive to compare the typical BEA research design described above with cognitive intervention studies. Cross-sectional BEA studies are of course by their nature different, but this comparison can be motivated by the fact that the goal of BEA studies is to document a phenomenon that is assumed to emerge from bilinguals' everyday practice with two or more languages, that is, from a sort of natural training that bilinguals do over time. When translating the typical BEA design into an intervention study, it would correspond to a posttest-only naturalistic group intervention setup. This represents a particularly weak research design. Besides the weaknesses related to natural groups listed above, no pre-post comparisons are possible and thus one does not know how comparable the groups were before one of the groups was exposed to L2. Moreover, in most published studies on BEA, the contents of the "intervention" (the features of individual bilingual experience) are largely unknown, as only the most general features such as age of L2 acquisition, the length of L2 exposure, and proficiency levels are reported. For example, it is often not known whether a bilingual's language use has involved frequent switching between L1 and L2, a factor that might play a role in the emergence of a putative BEA. When considering for a moment the typical cross-sectional BEA studies from this perspective, it is evident that if the goal is to reveal some kind of intervention effects, a study that does not employ randomization of the participants into training and control groups, fails to describe the contents of the intervention in any detail, and provides only posttraining data on the dependent variables, cannot provide any conclusive evidence. This is nevertheless the situation with most previous studies on BEA, including those conducted by ourselves (Soveri, Laine, Hämäläinen \& Hugdahl, 2011; Karlsson et al., 2015). 
2. Theory. In a recent commentary, Hartsuiker (2016) cogently pointed out the fundamental theoretical challenges faced with BEA research: "[..] the problem is that we lack precise characterizations of the source domain, the transfer process, and the target domain. Hence, we have no theory that predicts what circumstances particularly engage language control, no theory of skill generalization, and no cognitive control theory that specifies what executive functions can be improved by such generalization.” (p. 336). It should be noted that this problem is by no means unique to BEA research. The lack of a detailed theory on the underlying mechanisms of change concerns other areas of cognitive intervention as well, such as the currently popular working memory training (e.g., Shipstead, Zicks, \& Engle, 2012). This state of affairs makes it difficult to formulate and test specific hypotheses related to BEA in a principled fashion. In turn, this leads to difficulties in falsifying theoretical claims, as they remain unspecific.

3. Measures. Key characteristics of bilingualism are often probed with survey questions, or a combination of surveys and objective measures of language skills. The most commonly employed bilingualism-related variables tap L1/L2 competence (proficiency, language dominance, preference), age of language acquisition, modes of acquisition, and current use of languages. Self-estimated language skills have been shown to correlate significantly with objective measures (e.g., Marian, Blumenfeld, \& Kaushanskaya, 2007), but evaluations of own behaviour nevertheless carry inherent limitations related e.g. to memory failures, demand characteristics, and the limits of conscious access. These limitations may become more apparent when self-ratings are used to probe more specific aspects of bilingual behaviour, such as frequency and type of language switches that will be discussed below. Potential measurement problems are not limited to bilinguals only: monolinguals' use of dialects is not necessarily probed, even though one could speculate that bidialectals may cognitively resemble bilinguals and their presence amongst monolingual controls could perhaps mitigate BEA (Kempe, Kirk \& Brooks, 2015; but see Kirk, Fiala, Scott-Brown, \& Kempe, 2014). Another potential issue is to which extent monolingual groups in modern societies 
are indeed monolingual, as they have often been exposed to foreign languages at school and through media.

In BEA research, executive functions have been assessed with a number of tasks. To avoid the language confound in mono- vs. bilingual comparisons, one has often employed nonverbal task versions. A significant challenge to BEA research is the fact that the reliability and validity of commonly used non-linguistic executive measures are far from optimal (see, e.g., Paap \& Greenberg, 2013; Paap \& Sawi, 2014; Soveri, Lehtonen, Karlsson, Lukasik, Antfolk \& Laine, 2016). These problems also reflect the fact that the mental architecture of executive functions remains unclear despite the influential division of executive functions into three closely interrelated domains (set shifting, inhibition of irrelevant information, and working memory updating) that was put forth by Miyake, Friedman, Emerson, Witzki, Howerter, and Wager, (2000) and that has been applied in BEA research as well. Even within these hypothetical executive domains, tasks that supposedly tap the same component do not necessarily correlate with each other (e.g., Jylkkä, Lehtonen, Lindholm, Kuusakoski, \& Laine, 2017). This most probably reflects task impurity, a major concern especially with executive tasks. This means that performance on an executive task is influenced by several factors: the targeted executive function, general executive resources (e.g., goal-maintenance), task-specific features, and measurement error (Snyder, Miyake, \& Hankin, 2015). Together with limited sets of executive tasks in many BEA studies, task impurity leads to unavoidable interpretational problems where it is very difficult to disentangle task-specific vs. more general effects. This is a concern not only in original studies but also in meta-analyses where one needs to make decisions on how to categorize the variety of executive measures that have been used. Lumping together executive tasks that actually tap different executive resources may distort meta-analytic results.

\section{Possible remedies}


The list of problems presented above is formidable, but it has not prevented researchers from seeking solutions and trying to move the field forward from the current controversy. Here we discuss some promising new approaches.

Concerning the research design issues, it is evident that a researcher cannot start randomizing children to mono- or bilingual surroundings in order to conduct a longer-term followup study. However, the three design concerns (lack of randomization, pre-post comparison, and well-defined intervention) listed above can be amended under special circumstances, especially with short-term interventions. In a recent study, Janus, Lee, Moreno, and Bialystok (2016) employed a combination of randomization and pretest matching to assign a group of 57 four- to sixyear-old children to a 20-day training program in either music or conversational French. While the two intervention groups for the most part showed similar progress on nonverbal executive tasks in the pre-post comparison (no other control group was employed), this study exemplifies the feasibility of a rigorous experimental design in BEA research that enables causal inferences. A similar randomized controlled trial setup could be employed e.g. with university students by using a waiting list control group if a given foreign language course could be taken at different phases of the studies. An intervention study can also address the effects of language switching training in bilinguals, as was recently demonstrated by Zhang, Kang, Wu, Ma, and Guo (2015). Likewise, one could study the possible effects of general task switching training on bilingual language switching performances, albeit transfer effects from practice with task switching have been variable (Grönholm-Nyman, Soveri, Rinne, Ek, Nyholm, Stigsdotter Neely, \& Laine, 2017). However, one potential caveat of these kind of randomized controlled trials is that the time needed for consistent BEA effects to emerge might exceed the practical time limits of such an experiment. Another concern is that intervention studies do not catch the richness of bilingual experience in natural contexts. For naturalistic settings, cross-lagged longitudinal study designs would be useful in examining the directional influences between bilingualism and executive functions over time. 
Moving to theory, the lack of any detailed, testable (falsifiable) theory on the underlying mechanisms of BEA is a substantial impediment to the research field. Chein and Schneider (2012) presented a general neurocognitive model on human learning and control, but they do not make any specific claims concerning bilingualism. Interestingly, based on the Chein \& Schneider model that links executive engagement to the early stages of learning, Paap (in press) made a hypothesis related to BEA. According to Paap's Controlled Dose hypothesis, executive functions are recruited only during L2 learning when L1 is clearly dominant and requires constant monitoring and inhibition in order to prevent intrusions when the intention is to speak L2. Thus, any potential boost to executive functions would be observable only during the early stages of L2 acquisition, after which the effect would dissipate. This hypothesis awaits empirical testing. There are also models on executive processing in the bilingual mind (Green \& Abutalebi, 2013), but what is still missing is a well-specified, dynamic learning model of the putative changes in cognitive control following L2 exposure.

While a detailed computational model on the dynamics of cognition-language interactions during L2 acquisition is lacking, single BEA-related hypotheses are useful in turning attention to the various features of individual bilingual experience where the mechanisms for a putative BEA must lie. However, BEA studies have typically sought to determine only the most general aspects of bilingual experience, namely L2 age of acquisition and the proficiency level reached. Admittedly, also these general factors could be relevant to BEA. The first factor can be linked to BEA by simply assuming that the longer the experience, the more training one has received in managing two competing language systems. However, this would not say anything about the learning mechanisms involved. With regard to the second general factor (level of proficiency in L1 and L2), one could for example hypothesize that the amount of training in attentional control a bilingual receives is related to the amount of interference the languages elicit against each other, with stronger L2 leading to higher L1-L2 interference and thus more intensive 
training in interference control. As regards the relationships between these two general variables and executive functioning, the evidence thus far is equivocal. Some researchers have reported that early bilingualism is associated with better executive performance (Luk, de Sa \& Bialystok, 2011) while others have not found a difference in executive functions between early vs. late bilinguals (Pelham \& Abrams, 2014). In the study by Linck, Hoshino and Kroll (2014), the more proficient L2 learners were found to exhibit reduced inhibitory control relative to the less proficient ones, while another recent study by Yow and $\mathrm{Li}$ (2015) reported that more balanced use and proficiency in the two languages is related to a better executive functioning.

Naturally enough, individual bilingual experiences vary along many more dimensions than just age of acquisition and the overall level of proficiency obtained. Delving into these dimensions is important in advancing our understanding not only on BEA, but on bilingual behaviours in general. This approach puts more emphasis on within-group analyses of bilinguals. Accordingly, there have been attempts to correlate the frequency and type of bilingual language switches (part of which are assumed to tax and thus train executive functions) with executive task performances, but these studies have yielded mixed results (e.g., Prior \& Gollan, 2011; Soveri, Rodríguez-Fornells, \& Laine, 2011; Verreyt, Woumans, Vandelanotte, Szmalec, \& Duyck, 2016; Paap, Myuz, Anders, Bockelman, Mikulinsky, \& Sawi, 2017). More specific predictions concerning the relationships between language switching and executive functions are provided by the Adaptive Control Hypothesis by Green and Abutalebi (2013). It separates between three broad interactive bilingual contexts that set different demands on executive functions: a single-language context (each language used in its own context, e.g., at home and at work), a dual-language context (each language used with different conversation partners), and a dense code-switching context (the two languages are often interleaved within single utterances). As these bilingual communicative contexts are coupled with quite different executive demands (and thus different opportunities for putative executive training), the predominant contexts in which a bilingual operates could affect the 
emergence of BEA. An interesting recent study by Hartanto and Yang (2016) on language switching and task switching in bilinguals tested this. Hartanto and Young observed executive (switch cost) benefits for bilinguals who employed their two languages within the same interactional contexts. Moreover, they reported that different types of language switches (intra- vs intersentential) had opposite associations with executive task switching costs: intersentential switches, considered to be more taxing for language control than intrasentential ones, were associated with smaller switch costs in a color-shape switching task. This study exemplifies the need for more fine-grained analyses of bilingual behaviours, in this case language switching. The underlying assumption in this research approach is that, for example, language switching and nonlinguistic task switching share executive resources. There are some recent studies that support this conclusion (e.g., Linck, Schwieter \& Sunderman, 2012), but the evidence is still quite limited.

Finally, with regard to the methods used in measuring bilingual behaviours, we believe that more detailed analyses along the lines described above call for new measures besides the application of self-ratings that have their limitations. With the use of digital techniques, one could go even further by collecting data of bilinguals' language behaviour online. We have recently explored bilingual language switching behaviour with the so-called Ecological Momentary Assessment via smartphones, collecting participant reports on their real-life language switching behaviour close in time to experience, several times per day (Jylkkä, Soveri, Laine \& Lehtonen, 2017). Innovative digital technologies make it nowadays possible to conduct also comprehensive objective assessment of everyday spoken language behaviours. The Language ENvironment Analysis system (LENA ${ }^{\mathrm{TM}}$ ) provides researchers with all-day digital recording and automated speech signal analysis (e.g., Canault, Le Normand, Foudil, Loundon, \& Thai-Van 2016). It is important to have these techniques tailored also for bilingualism research. All these techniques should preferably utilize the individual differences approach so that specific aspects of bilingual experience are analyzed in a multivariate fashion as continuous variables, as they can vary 
considerably from person to person. As regards executive measures, the task impurity issue unfortunately prevails. One way to try to circumvent this is to have several tasks per executive domain and employ composite scores or factor score estimates that should reflect the underlying construct more reliably (Schmiedek, Lövdén \& Lindenberger, 2014).

\section{Conclusions}

In this short review, we have highlighted important methodological and theoretical problems that have plagued many previous studies on BEA and contributed to the present controversy on its existence. An important way forward is to focus much more research attention on the individual features of bilingual experience, as this is where the putative cognitive effects stem from. While the earlier focus has been on a bilingual advantage (i.e., in comparing bilinguals to monolinguals), the research approach outlined here deals more with the interplay of language behaviours and cognition within bilinguals. This comes back to the idea of bilingualism as a research avenue for language learning mechanisms, language-cognition interfaces, and brain plasticity in general.

\section{Acknowledgments}

This work was supported by the Academy of Finland [grants \#260276 and \#288880];

the Åbo Akademi University Endowment [the BrainTrain project]; the Emil Aaltonen Foundation; and the University of Helsinki [3-year grants]. 


\section{References}

Abutalebi, J., Canini, M., Della Rosa, P.A., Green, D.W., Weekes, B.S. (2015) The neuroprotective effects of bilingualism upon the inferior parietal lobule: A structural neuroimaging study in aging Chinese bilinguals. Journal of Neurolinguistics, 33, 3-13.

http://dx.doi.org/10.1016/j.jneuroling.2014.09.008.

Adesope, O.O., Lavin, T., Thompson, T., \& Ungerleider, C. (2010). A systematic review and metaanalysis of the cognitive correlates of bilingualism. Review of Educational Research, 80, 207-245. doi: 10.3102/0034654310368803.

Alladi, S., Bak, T. H., Duggirala, V., Surampudi, B., Shailaja, M., Shukla, A. K., ... \& Kaul, S. (2013). Bilingualism delays age of onset of dementia, independent of education and immigration status. Neurology, 81 (22), 1938-1944. doi: 10.1212/01.wnl.0000436620.33155.a4.

Antón, E., Duñabeitia, J.A., Estévez, A., Hernández, J.A., Castillo, A., Fuentes, L.J., Davidson, D.J., \& Carreiras, M. (2014). Is there a bilingual advantage in the ANT task? Evidence from children. Frontiers in Psychology, 5:398. doi: 10.3389/fpsyg.2014.00398.

Baum, S. \& Titone, D. (2014). Moving toward a neuroplasticity view of bilingualism, executive control and aging. Applied Psycholinguistics, 5, 857 - 894.

Bialystok, E. (2015). Bilingualism and the development of executive function: the role of attention. Child Development Perspectives, 2, 117-121. doi: 10.1111/cdep.12116. 
Bialystok, E., Abutalebi, J., Bak, T. H., Burke, D. M., \& Kroll, J. (2016). Aging in two languages: Implications for public health. Ageing Research Reviews, 27, 56-60. doi: 10.1016/j.arr.2016.03.003.

Bialystok, E., Craik, F.I.M, \& Freedman, M. (2007). Bilingualism as protection against the onset of symptoms of dementia. Neuropsychologia, 45, 459-464. doi:

10.1016/j.neuropsychologia.2006.10.009.

Bialystok, E., Craik, F.I.M., \& Luk, G. (2012) Bilingualism: consequences for mind and brain. Trends in Cognitive Sciences, 16, 240-250. doi: 10.1016/j.tics.2012.03.001.

Canault, M., Le Normand, M.-T., Foudil, S., Loundon, N., Thai-Van, H. (2016) Reliability of the Language ENvironment Analysis system (LENA ${ }^{\mathrm{TM}}$ ) in European French. Behavioral Research Methods, 48, 1109-1124.

Costa, A., \& Sebastián-Gallés, N. (2014). How does the bilingual experience sculpt the brain? Nature Reviews Neuroscience, 15, 336-345. doi: 10.1038/nrn3709.

De Bruin, A., Treccani, B., \& Della Sala, S. (2014). Cognitive advantage in bilingualism: an example of publication bias? Psychological Science, 26(1), 99-107. doi: $10.1177 / 0956797614557866$.

Duñabeitia, J. A., Hernández, J. A., Antón, E., Macizo, P., Estévez, A., Fuentes, L. J., \& Carreiras, M. (2014). The inhibitory advantage in bilingual children revisited: Myth or reality? Experimental Psychology, 61(3), 234-251. doi: 10.1027/1618-3169/a000243. 
Garbin, G., Sanjuan, A., Forn, C., Bustamante, J.C., Rodriguez-Pujadas, A., Belloch, V., Hernandez, M., Costa, A., \& Avila, C. (2010) Bridging language and attention: brain basis of the impact of bilingualism on cognitive control. Neuroimage, 53, 1272-1278. doi: 10.1016/j.neuroimage.2010.05.078.

García-Penton, L., Fernández García, Y, Costello, B. Duñabeitia, J. A., \& Carreiras, M. (2015). The neuroanatomy of bilingualism: how to turn a hazy view into the full picture. Language, Cognition and Neuroscience, 31 (3), 1-25. doi: 10.1080/23273798.2015.1068944.

Gathercole, V.C., Thomas, E.M., Kennedy, I., Prys C., Young, N., Viñas Guasch, N., Roberts, E.J., Hughes, E.K., \& Jones, L. (2014) Does language dominance affect cognitive performance in bilinguals? Lifespan evidence from preschoolers through older adults on card sorting, Simon, and metalinguistic tasks. Frontiers in Psychology, 5:11. doi: 10.3389/fpsyg.2014.00011.

Green, D. W., \& Abutalebi, J. (2013). Language control in bilinguals: The adaptive control hypothesis. Journal of Cognitive Psychology, 25, 515-530. doi: 10.1080/20445911.2013.796377.

Grönholm-Nyman, P., Soveri, A., Rinne, J.O., Ek, E., Nyholm, A., Stigsdotter Neely, A., \& Laine, M. (2017) Limited effects of set shifting training in healthy older adults. Frontiers in Aging Neuroscience, 69. doi: 10.3389/fnagi.2017.00069

Hartanto, A., \& Yang, H. (2016). Disparate bilingual experiences modulate task-switching advantages: A diffusion-model analysis of the effects of interactional context on switch costs. Cognition, 150, 10-19. doi: 10.1016/j.cognition.2016.01.016.

Hartsuiker, R. J. (2015). Why is it pointless to ask under which specific circumstances the bilingual advantage occurs. Cortex, 73, 336-337. doi: 10.1016/j.cortex.2015.07.018. 
Hilchey, M.D., \& Klein, R.M. (2011) Are there bilingual advantages on nonlinguistic interference tasks? Implications for the plasticity of executive control processes. Psychonomic Bulletin \& Review, 18, 625-658. doi: 10.3758/s13423-011-0116-7.

Hilchey, M., Saint-Aubin, J., \& Klein, R. (2015). Does bilingual exerciseenhance cognitive fitnessin traditional non-linguistic executive processing tasks? In J. Schwieter (Ed.), The Cambridge Handbook of Bilingual Processing (Cambridge Handbooks in Language and Linguistics, pp. 586613). Cambridge: Cambridge University Press. doi:10.1017/CBO9781107447257.026.

Hämäläinen, S. Sairanen, V., Leminen, A., \& Lehtonen, M. (2017) Bilingualism modulates the white matter structure of language-related pathways. NeuroImage, 152, 249-257. http://dx.doi.org/10.1016/j.neuroimage.2017.02.081.

Janus, M., Lee, Y., Moreno, S., \& Bialystok, E. (2016) Effects of short-term music and secondlanguage training on executive control. Journal of Experimental Child Psychology, 144, 84-97. doi: 10.1016/j.jecp.2015.11.009.

Jylkkä, J., Lehtonen, M., Lindholm, F., Kuusakoski, A., \& Laine, M. (2017) The relationship between general executive functions and bilingual switching and monitoring in language production. Bilingualism: Language and Cognition. Epublication ahead of print. doi: https://doi.org/10.1017/S1366728917000104.

Jylkkä, J., Soveri, A., Laine, M., \& Lehtonen, M. (2017) Assessing bilingual language switching behavior with Ecological Momentary Assessment. Third Learning and Plasticity Meeting, April 25, 2017, Äkäslompolo, Finland. 
Karlsson, L.C., Soveri, A., Räsänen, P., Kärnä, A., Delatte, S., Lagerström, E., Mård, L., Steffansson, M., Lehtonen, M., \& Laine, M. (2015) Bilingualism and performance on two widely used developmental neuropsychological test batteries. PLoS ONE, 10(4): e0125867, 1-11. doi:10.1371/journal.pone.0125867.

Kempe, K., Kirk, N.W., \& Brooks, P.J. (2015) Revisiting theoretical and causal explanations for the bilingual advantage in executive functioning. Cortex, 73, 342-344.

Kirk, N.W., Fiala, L., Scott-Brown, K.C., \& Kempe, V. (2014) No evidence for reduced Simon cost in elderly bilinguals and bidialectals. Journal of Cognitive Psychology, 26(6), 640-648. https://doi.org/10.1080/20445911.2014.929580.

Lehtonen, M., Soveri, A., Laine, A., Järvenpää, J., De Bruin, A. \& Antfolk, J. (in press) Is bilingualism associated with enhanced executive functioning? A meta-analytic review. Psychological Bulletin.

Linck, J.A., Hoshino, N., \& Kroll, J.F. (2008) Cross-language lexical processes and inhibitory control. Mental Lexicon, 3, 349-374. doi: 10.1075/ml.3.3.06lin.

Linck, J. A., Schwieter, J. W., \& Sunderman, G. (2012) Inhibitory control predicts language switching performance in trilingual speech production. Bilingualism: Language and Cognition, 15, 651-662. doi: https://doi.org/10.1017/S136672891100054X.

Ljungberg, J. K., Hansson, P., Adolfsson, R., \& Nilsson, L.-G. (2016) The effect of language skills on dementia in a Swedish longitudinal cohort. Linguistic Approaches to Bilingualism, 6, 190-204. doi 10.1075/lab.14031.lju. 
Luk, G., de Sa, E., \& Bialystok, E. (2011) Is there a relation between onset age of bilingualism and enhancement of cognitive control? Bilingualism: Language and Cognition, 14, 588-595. doi:10.1017/S1366728911000010.

Marian, V., Blumenfeld, H.K., \& Kaushanskaya, M. (2007) The Language Experience and Proficiency Questionnaire (LEAP-Q): assessing language profiles in bilinguals and multilinguals. Journal of Speech Language and Hearing Research, 50, 940-967.

Mechelli, A., Crinion, J.T., Noppeney, U., O'Doherty, J., Ashburner, J., Frackowiak, R.S., \& Price, C.J. (2004) Neurolinguistics: structural plasticity in the bilingual brain. Nature, 431, 757.

Miyake, A., Friedman, N. P., Emerson, M. J., Witzki, A. H., Howerter, A., \& Wager, T. D. (2000). The unity and diversity of executive functions and their contributions to complex "frontal lobe" tasks: A latent variable analysis. Cognitive Psychology, 41, 49-100. doi:10.1006/cogp.1999. 0734.

Morton, J.B., \& Harper, S.N. (2007) What did Simon say? Revisiting the bilingual advantage. Developmental Science, 10, 719-726.

Mukadam, N., Sommerlad, A., \& Livingston, G. (2017) The relationship of bilingualism compared to monolingualism to the risk of cognitive decline or dementia: A systematic review and metaanalysis. Journal of Alzheimers Disease, 58, 45-54. doi: 10.3233/JAD-170131.

Mårtensson J1, Eriksson J, Bodammer NC, Lindgren M, Johansson M, Nyberg L, \& Lövdén M. (2012) Growth of language-related brain areas after foreign language learning. Neuroimage, 63, 240-244. doi: 10.1016/j.neuroimage.2012.06.043. 
Paap, K. (in press) Bilingualism in cognitive science. In A. De Houwer \& L. Oretga, Eds., Handbook of Bilingualism. Cambridge: Cambridge University Press.

Paap, K. R., \& Greenberg, Z. I. (2013). There is no coherent evidence for a bilingual advantage in executive processing. Cognitive Psychology, 66, 232-258. doi: 10.1016/j.cogpsych.2012.12.002. Paap, K.R., Johnson, H.A., \& Sawi, O. (2014) Are bilingual advantages dependent upon specific tasks or specific bilingual experiences? Journal of Cognitive Psychology, 26, 615-639. http://dx.doi.org/10.1080/20445911.2014.944914.

Paap, K. R., Johnson, H. A., and Sawi, O. (2015). Bilingual advantages in executive functioning either do not exist or are restricted to very specific and undetermined circumstances. Cortex, 69, 265-278. doi: 10.1016/j.cortex.2015.04.014.

Paap, K.R., Myuz, H.A., Anders, R.T., Bockelman, M.F., Mikulinsky, R., \& Sawi, O.M. (2017) No compelling evidence for a bilingual advantage in switching or that frequent language switching reduces switch cost. Journal of Cognitive Psychology, 29 (2), 89-112. DOI: 10.1080/20445911.2016.1248436.

Paap, K. R., \& Sawi, O. (2014) Bilingual advantages in executive functioning: problems in convergent validity, discriminant validity, and the identification of the theoretical constructs. Frontiers in Psychology, 5, 962. doi: 10.3389/fpsyg.2014.00962.

Paap, K., Johnson, H., Bockelman, M., Cushing, D., \& Sawi, O. (2014) 20,000 Flanker Trials: Are the Effects Reliable, Robust, and Stable? Poster presented at the 26th Convention of the Association of Psychological Science, San Francisco, CA.

Pelham, S.D., \& Abrams, L. (2014) Cognitive advantages and disadvantages in early and late bilinguals. Journal of Experimental Psychology: Learning, Memory, and Cognition, 40, 313-325. doi: $10.1037 / \mathrm{a} 0035224$. 
Perani, D., \& Abutalebi, J. (2005). The neural basis of first and second language processing. Current Opinion in Neurobiology, 15, 202-206. doi: 10.1016/j.conb.2005.03.007.

Prior, A., \& Gollan, T. (2011). Good language-switchers are good task-switchers: Evidence from Spanish-English and Mandarin-English bilinguals. Journal of International Neuropsychological Society, 17, 1-10. doi: 10.1017/S1355617711000580.

Ratiu. I., Hout, M.C., Walenchok, S.C., Azuma, T., \& Goldinger, S.D. (2017) Comparing visual search and eye movements in bilinguals and monolinguals. Attention, Perception, \& Psychophysics 79(6), 1695-1725. doi: 10.3758/s13414-017-1328-3.

Saer, D. J. (1923). The effect of bilingualism on intelligence. British Journal of Psychology, 14, 2538.

Schmiedek, F., Lövdén, M., \& Lindenberger, U. (2014) A task is a task is a task: putting complex span, n-back, and other working memory indicators in psychometric context. Frontiers in Psychology, 5, 1475. doi: 10.3389/fpsyg.2014.01475.

Shipstead, Z., Hicks, K.L., Engle, R.W. (2012) Cogmed working memory training: Does the evidence support the claims? Journal of Applied Research in Memory and Cognition, 1, 185-193.

Snyder, H. R., Miyake, A., \& Hankin, B. L. (2015) Advancing understanding of executive function impairments and psychopathology: Bridging the gap between clinical and cognitive approaches. Frontiers in Psychology, 6. https://doi.org/10.3389/fpsyg.2015.00328. 
Soveri, A., Laine, M., Hämäläinen, H., \& Hugdahl, K. (2011) Bilingual advantage in attentional control: evidence from the forced-attention dichotic listening paradigm. Bilingualism: Language and Cognition, 14, 371-378. doi: 10.1017/S1366728910000118.

Soveri, A., Lehtonen, M., Karlsson, L.C., Lukasik, K., Antfolk, A., \& Laine, M. (2016) Test-retest reliability of five frequently used executive tasks in healthy adults. Applied Neuropsychology: Adult. Publication ahead of print. http://dx.doi.org/10.1080/23279095.2016.1263795.

Soveri, A., Rodríguez-Fornells, A., \& Laine, M. (2011) Is there a relationship between language switching and executive functions in bilingualism? Introducing a within-group analysis approach. Frontiers in Psychology, 2, 183, 1-8. doi 10.3389/fpsyg.2011.00183.

Verreyt, N., Woumans, E., Vandelanotte, D., Szmalec, A., \& Duyck, W. (2016). The influence of language switching experience on the bilingual executive control advantage. Bilingualism: Language and Cognition, 19 (1), 181-190.

Yang, H., Hartanto, A., \& Yang, S. (2016) The complex nature of bilinguals' language usage modulates task-switching outcomes. Frontiers in Psychology, 7M, 560. doi: 10.3389/fpsyg.2016.00560.

Yow, W.Q., \& Li X. (2015) Balanced bilingualism and early age of second language acquisition as the underlying mechanisms of a bilingual executive control advantage: why variations in bilingual experiences matter. Frontiers in Psychology, 26, 6:164. doi: 10.3389/fpsyg.2015.00164. 
Zhang, H., Kang, C., Wu, Y., Ma, F., \& Guo, T. (2015) Improving proactive control with training on language switching in bilinguals. Neuroreport, 26, 354-359.

Zhou, B., \& Krott, A. (2016). Data trimming procedure can eliminate bilingual cognitive advantage. Psychonomic Bulletin \& Review, 23, 1221-1230. doi: 10.3758/s13423-015-0981-6. 